Article

\title{
Optimising Parameters for Expanded Polystyrene Based Pod Production Using Taguchi Method
}

\author{
Sheikh Imran Ishrat $1, * \mathbb{C}$, Zahid Akhtar Khan ${ }^{2}$, Arshad Noor Siddiquee ${ }^{2}$, \\ Irfan Anjum Badruddin ${ }^{3, * \mathbb{C}}$, Ali Algahtani ${ }^{3,4}$, Shakeel Javaid ${ }^{5}$ and Rajan Gupta ${ }^{6}$ \\ 1 Department of Enterprise and Digital Innovation, Ara Institute of Canterbury, 130 Madras St., \\ Christchurch-8011, Canterbury, New Zealand \\ 2 Department of Mechanical Engineering, Jamia Millia Islamia, New Delhi-110025, India \\ 3 Department of Mechanical Engineering, College of Engineering, King Khalid University, Abha 61421, \\ Saudi Arabia \\ 4 Research Center for Advanced Materials Science (RCAMS), King Khalid University, Abha-61413, Asir, \\ Saudi Arabia \\ 5 Department of Statistics and Operations Research, Aligarh Muslim University, Aligarh-202002, \\ Uttar Pradesh, India \\ 6 EPS Foam Ltd., 3/70 Shortland St., Christchurch-8061, New Zealand \\ * Correspondence: imran.ishrat@ara.ac.nz; magami.irfan@gmail.com or irfan@kku.edu.sa
}

Received: 15 August 2019; Accepted: 9 September 2019; Published: 14 September 2019

\begin{abstract}
Expanded polystyrene (EPS) is used in the building and construction industry for insulation and under flooring purposes. The objective of the study is to investigate the impact of the application of the total quality management (TQM) technique on the significant parameters of the pod production process in a New Zealand based EPS manufacturing facility. In this work, Taguchi's $\mathrm{L}_{27}$ orthogonal array $(\mathrm{OA})$ is considered for conducting experiments through three input parameters i.e., weight of untreated beads, batch duration, and temperature is investigated. Based on the results, the analyses are carried out while using statistical approaches, such as analysis of the means (ANOM) and analysis of variance (ANOVA). The results from confirmatory experiment indicate that, at optimal parameters setting (17 kg of untreated bead, $130 \mathrm{~s}$ of batch duration and $155^{\circ} \mathrm{F}$ of temperature), a reasonably streamlined pod manufacturing process can be achieved for sustainable operations.
\end{abstract}

Keywords: Expanded polystyrene; Taguchi method; construction industry; total quality management

\section{Introduction}

In the last few decades, the focus on Total Quality Management (TQM) philosophy has significantly gained attention among industry practitioners and academics. The emphasis is on the application of the TQM theories to manage and improve the various organisational aspects, so as to deliver a quality outcome i.e., a good or service to the end-user. Organisations use a multitude of TQM tools and techniques to continuously improve process outcomes [1]. TQM has evolved in different quality domains from the substantial contributions of Shewhart (Statistical Quality Control), Deming (Process Control Quality), Juran (Quality Management), Feigenbaum (Total Quality Control), Crosby (Quality Cost), Ishikawa (Preventive Quality), and Taguchi (Design Quality) [2-4]. Moreover, different TQM methodologies have been successfully implemented in various industrial settings across distinct organisational levels [5,6]. With the increased material, energy, and operational costs, organisations continuously look for opportunities to optimise their operations to gain competitive advantage [7]. Based on Taguchi's methodology, this paper describes a case study in an industrial setting, which is facing challenges in producing high-quality products that are sensitive to various causes of variation. 
In the building and construction industry, expanded polystyrene (EPS) is extensively used to produce pods and blocks for under floorings and insulation panels, which are the two essential components that are required in the buildings. A pod is a semi-hollow grid component, which resembles with a honeycomb, whereas a block is a solid module that is cut into sheets to produce insulation panels. Post February 2011 earthquakes in Christchurch (New Zealand), there has been an ongoing mass scale rebuild process in the city to redevelop the infrastructure for commercial and residential purposes. New materials, possessing earthquake resistant properties, are being produced and used in buildings to minimise the impact of any such natural calamity in future. As a result, there is a surge in the demand for new construction and building materials that can withstand earthquake shocks to reduce sufferings of the various affected community segments.

In this paper, a pod-manufacturing process is considered in the EPS supply chain to study the impact of the various process parameters on the quality of the pod. The variation in the pod manufacturing process with regard to the response variable i.e., weight of the expanded beads forms the basis for this study. In general, EPS is also suitable for manufacturing various types of packaging material for consumer goods, including foodstuff, horticulture, and electronics. EPS, which is a synthetic polymer made from the styrene monomer, is extremely light, durable, and resistant to moisture. On the daily basis, a considerable amount of EPS based materials are produced, a portion of which results in waste. This leads to the increase in carbon footprint, which eventually ends up affecting the environment. Furthermore, variation in the manufacturing practices or non-compliance to the standards and procedures might lead to increased processing time and cost, which might affect the sustainability aspects across the EPS chain. EPS has been the focus of work for academics for long. Horvath [8] provided useful information regarding the various mechanical, physical, and thermal properties of the EPS. Chen and Liu [9] investigated the properties of reinforced concrete structures with respect to EPS and styrene-butadine rubber by considering two types of spherical EPS beads to test the strength of polymer-cement ratios. Whereas, Magalhães and Lago [10] studied the impact of Titanium dioxide $\left(\mathrm{TiO}_{2}\right)$ on EPS surface through a photocatalytic study. Kannan et al. [11] addressed the issues that surround the decomposition of EPS by considering heating rate and gaseous environment as the parameters. The studies that were conducted by Varnagiris et al. [12] and Shirazi et al. [13] analysed the moisture adsorption and resistance aspects of coated EPS foam beads under mechanical stresses, such as shear and compressive stresses. Furthermore, EPS has been the topic of interest for researchers in various other applications areas. For instance, various aspects of EPS have been explored in different applications such as nano-manufacturing [14,15], construction [16,17], composite materials [18,19], waste [20,21], and recycling [22].

In view of the utility of the EPS pods, especially in the construction industry, it is of utmost important to ensure the quality of the final deliverable. It has been observed from the literature that information pertaining to the systematic experimental investigation of the effect of the various pod production process parameters on the quality of pods is lacking. Keeping this in view, an attempt has been made in this paper to explore effect of the critical pod production process parameters on the pod quality that is measured in terms of weight of the expanded beads. Further, this paper also aims at determining the optimal combination of the process parameters while using Taguchi's design of experiment. If the pod production process is operated at optimum levels of the process parameters then it would produce high quality pods and helps to mitigate the ripple effects of poor quality down the chain. The pod production process was observed and experiments were conducted to study the effects of critical factors in producing pods at one of the major New Zealand based EPS facilities. The study that is presented in this paper is expected to provide useful information to the stakeholders who are associated with EPS pod production.

\section{The Pod Production Process}

A pod is produced using EPS, which is a synthetic polymer. As stated by the operators at the production facility, the pod production process starts with the acquisition of raw material in the form 
of resin or crystals from the upstream suppliers in the chain. The resin is a tiny pentane or butane bead (Figure 1) with a diameter that ranges from $0.2 \mathrm{~mm}$ to $2.0 \mathrm{~mm}$. The resin is procured in large bags that contain between $800 \mathrm{~kg}$ to $850 \mathrm{~kg}$ of raw material i.e., polymeric expandable beads (Figure 2).

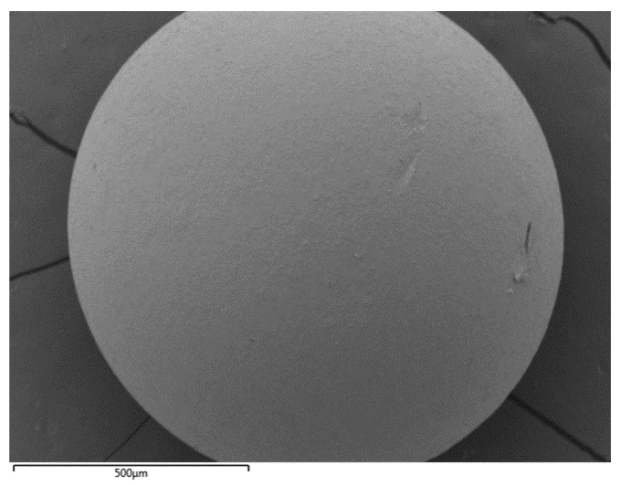

Figure 1. Scanning Electron Microscope (SEM) image of an untreated bead at magnification 100 $\times$ and accelerating voltage of $5 \mathrm{kV}$.

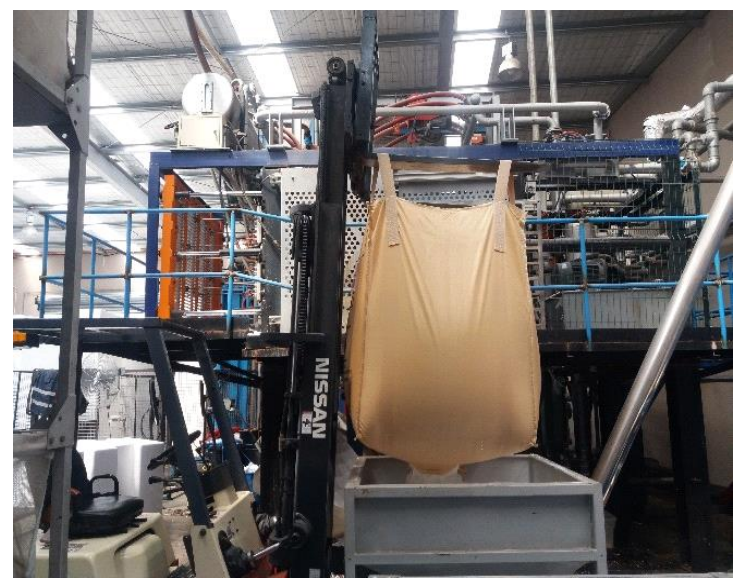

Figure 2. A bag containing expanded polystyrene (EPS) resins.

These tiny beads are placed in the bead expander machine (Figure 3) from hopper filler through a suction pipe. The raw material is contained in the machine in different quantities through a censor-controlled mechanism. Depending on the type of product (pod or block) to be produced, the resins are released to the main chamber of the bead expander machine, where they are transformed into expanded beads. In the main chamber, the resin is exposed to the steam at high temperature that transforms it to as many as 40 times its original size; turning the resin into a hollow bead.

Transforming the resin into beads in the bead expander machine is one of the most important steps in the pod production process. This transformation is subjected to variations, and therefore it leads to different quality issues. In this phase, a set of sequential activities, such as establishing the resin quantity, filling the resin in the main chamber, pre-heating, heating, stabilising, and discharging of the beads is carried out. This is followed by closing the door of the chamber and waiting for few seconds for the next batch to start. However, before the next batch is processed, the weight of the expanded beads is recorded to ensure that it conforms to the desired specifications. If the desired weight is obtained, then the process is continued, otherwise the parameters are adjusted to suit the output requirements. 


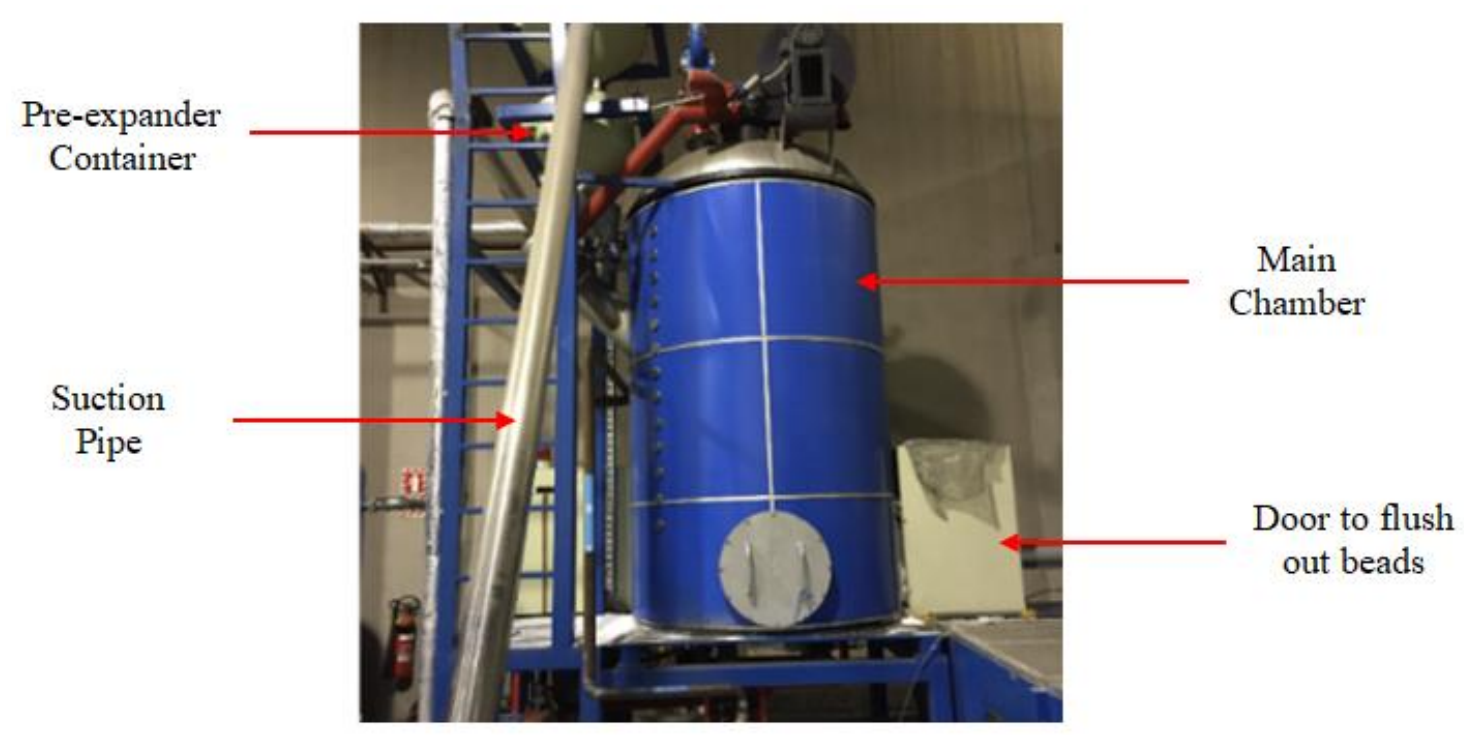

Figure 3. The bead expander machine.

Based on the conversation with the operators, Figure 4 presents a flow chart of the process associated with the bead expander machine to illustrate the sequential activities that are involved at this significant stage of the pod production process. Among these activities, during the transformation process, parameters, such as material quantity, temperature, and batch time, play significantly important role in converting polystyrene resins into the beads of foam. Due to a change in these parameters, beads of foam shrink or expand, leading to variation in the weight of the beads affecting the quality of the pod. In this work, different combinations of the parameters were studied along with their impact on the response variable to minimise the variation in the pod manufacturing process. The transformation process is operated through the state-of-the-art touch screen Programmable logic controller (PLC) mechanism that is built-in to the bead expander machine. The outcome of this process is a bead containing more than $95 \%$ air content in it. In pod manufacturing, consistency in the output can be achieved and improved by standardising the significant input parameters of the bead expander machine.

Once the beads are formed, they are allowed to cool down and are dried in large tanks (Figure 5), preferably at least for a day. The cooling process, to some extent, removes, pentane, or butane present inside the puffed beads.

However, the expanded beads are not kept in the tanks beyond two days, as they may lose the chemical component significantly, which may have an impact on the final deliverable. In this case, the beads might not shrink or expand in the shape moulding machine appropriately when exposed to cross-steam, which helps in binding the beads to produce pods or blocks. As evident from Figure 6, the over exposure of the beads to the external environment might severely affect their capacity to bind with one another and limits their ability to expand or shrink during the moulding stage. After the cooling process, the vacuum created within the beads is diffused to attain greater elasticity for the moulds. At this stage, the diffused beads are exposed to cross steam in the moulding machine, so that they bind together to form the desired shapes. 


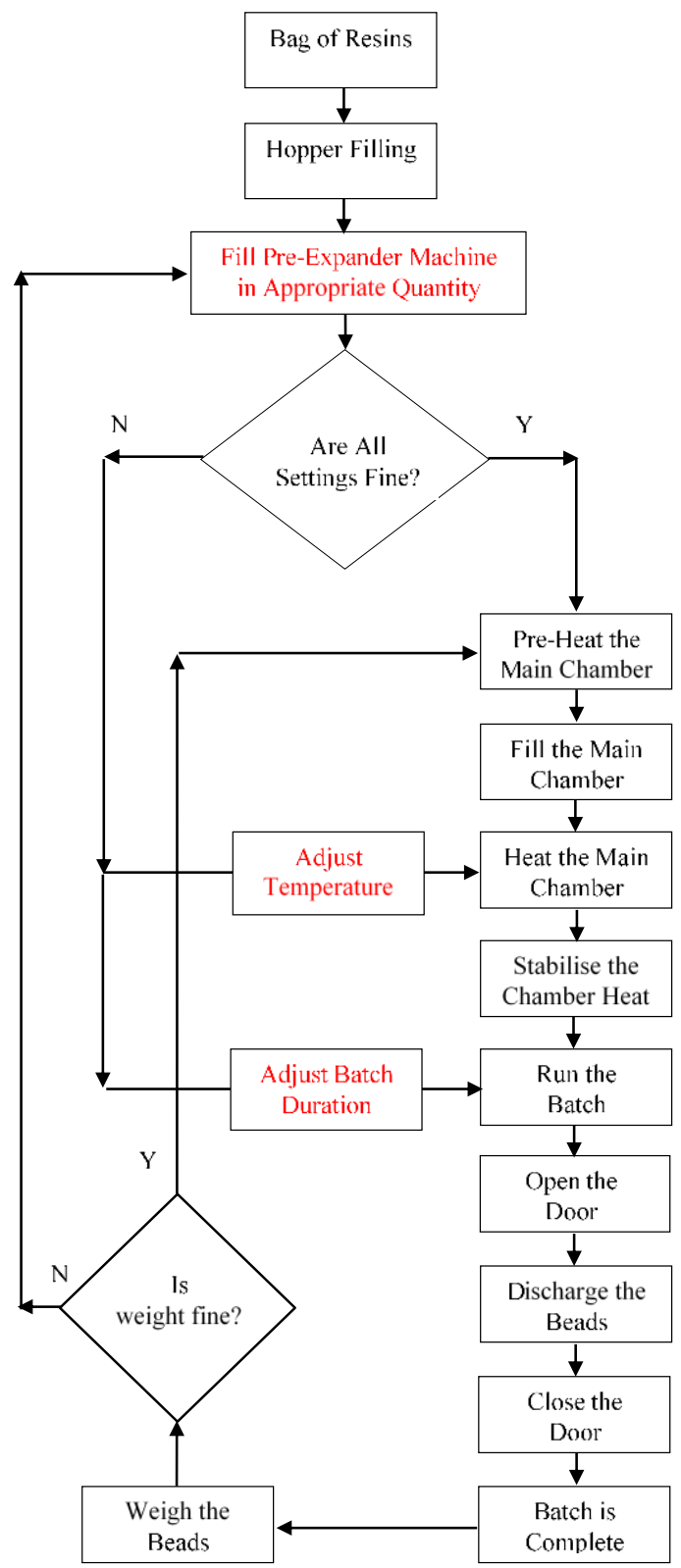

Figure 4. Flow chart of the bead production process.

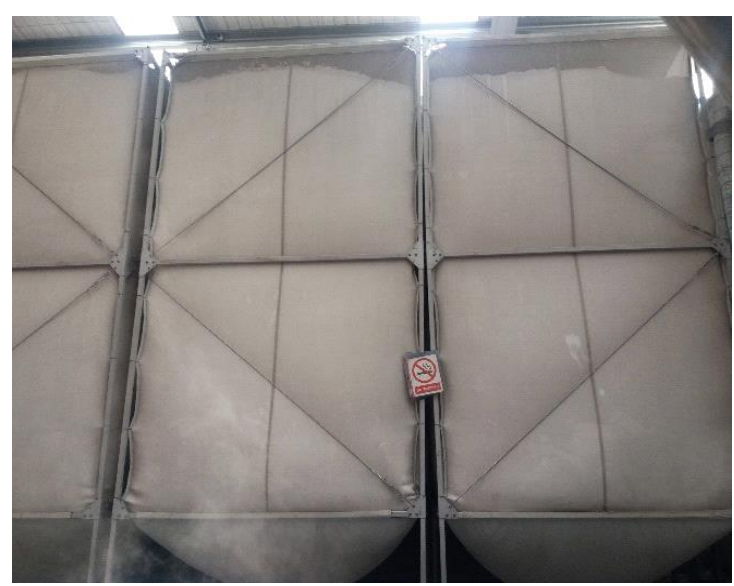

Figure 5. Large tanks used to cool the beads. 


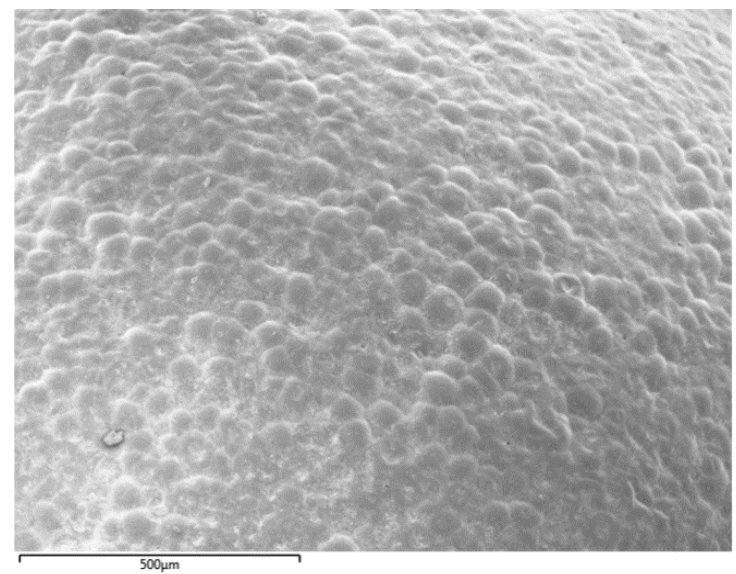

Figure 6. SEM view of an over exposed bead.

Two types of cross-streams are used in the moulding process; type $\mathrm{P}$ and $\mathrm{Q}$, which represents the portion of the pod where the cross-streams are exposed on it during the moulding process. Type $\mathrm{P}$ is used for the front portion of the pod in which the stronger cross-steam $\left(\mathrm{P}_{1}\right)$ targets the four corners of the pod, whereas the relatively milder cross-steam $\left(\mathrm{P}_{2}\right)$ captures the mesh structure. Type $Q$ cross-steam is exposed at the back of the pod with different intensities $\left(Q_{1}\right.$ and $\left.Q_{2}\right)$, wherein the four back corners of the pod are captured by $Q_{1}$ and the even back surface is exposed to $Q_{2}$. It is observed that, if the beads vary in quality in regards to weight, then the beads may not bind together, properly compromising the quality of the pod. In this case, the pod is not good enough to be used for the intended purpose (under flooring) and it may end up with little use (packaging material) or no use (scrap). For pods, a greater density of the beads is desired to achieve better flexibility in the product. In Figure 7, a manufactured pod released from the moulding machine is shown. The final product (Figure 8) depends on the weight of the expanded beads. Three different sizes of pods are produced to suit distinct customer requirements, as presented in Table 1.

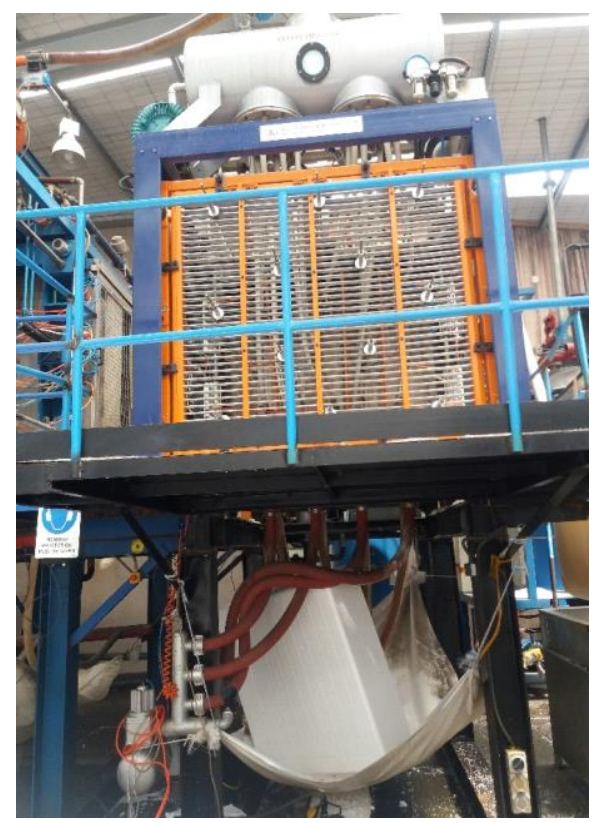

Figure 7. A pod in the making through the shape moulding machine.

For all types of pods, the standard weight for beads of foam is $14 \mathrm{~g}$ in a 1 litre capacity container. However, for blocks it is different for standard, high, and very high grades i.e., $18 \mathrm{~g}, 24 \mathrm{~g}$, and $27 \mathrm{~g}$, 
respectively. After the pod is manufactured, it is tested with respect to quality specifications and is shipped to the construction site to be laid in the foundation of the building (Figure 9).

Table 1. Dimensions of pods.

\begin{tabular}{cccc}
\hline \multirow{2}{*}{ No. } & \multicolumn{3}{c}{ Dimensions of Pods (in mm) } \\
\cline { 2 - 4 } & Length & Breadth & Height \\
\hline 1 & 1100 & 1100 & 200 \\
2 & 1100 & 1100 & 220 \\
3 & 1100 & 1100 & 300 \\
\hline
\end{tabular}

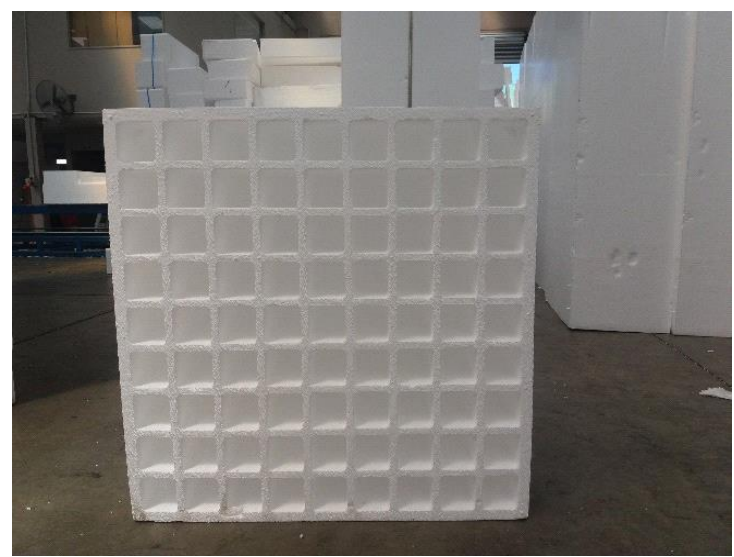

Figure 8. Front portion of a finished pod.

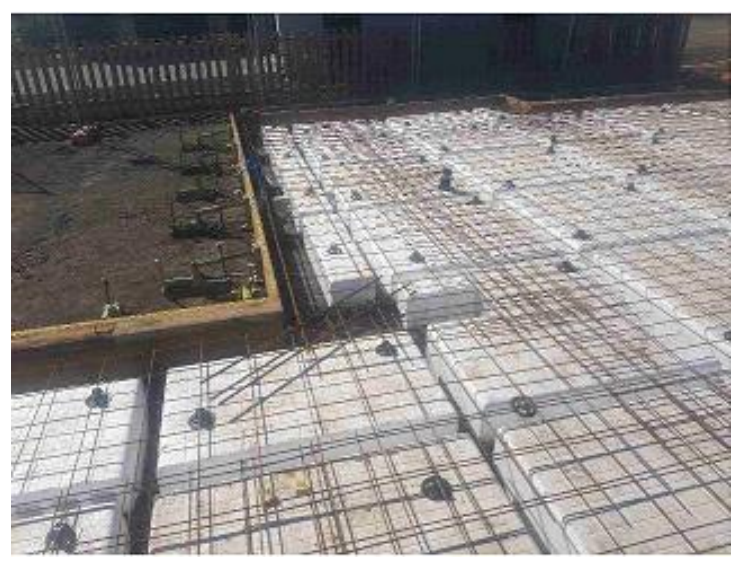

Figure 9. Pods laid at a construction site.

\section{Methodology}

Experimental design techniques are used to study the behaviour and impact of the significant input parameters on the response variables in developing new products, improving existing product designs, and achieving process improvement. Regarding an experimental design based work, Hinkelmann [23] and Davim [24] suggested that, for more comprehensive study, a full factorial design should be preferred, as it explores all of the possibilities associated with the experimental set up. In this study, Taguchi methodology is used to investigate the effect of controllable parameters of Pod production on the weight of the bead in order to obtain optimal combination of the parameters, which yields minimum weight of the expanded beads. The Taguchi method makes use of orthogonal arrays (OAs) 
for designing the experiments. This method is based on the additive cause and effect model, which can be explained, as follows:

Suppose that a process is affected by two factors i.e., A and B, and the effects of factor A and factor $B$ on the response variably $Y$ are represented by $\alpha$ and $\beta$, respectively. Taguchi suggested that in many practical situations the effects of factor A and factor B, also known as main effects, can be represented by an additive cause and effect model that is given in Equation (1).

$$
Y_{i j}=\mu+\alpha_{i}+\beta_{j}+e_{i j}
$$

where, $\mu=$ mean value of $Y$ within the experiment range, $\alpha_{i}$ and $\beta_{j}=$ main effects of factor $A$ and factor $\mathrm{B}$, respectively, $\mathrm{e}_{\mathrm{ij}}=$ error term.

The Taguchi method is a partial factorial design of experiment that is widely used by researchers for design and process optimization. When compared to other methods, its advantage is that it provides the desired results with minimum number of experiments, which results in significant savings of resources, such as money, time, etc. The Taguchi method is a well-celebrated technique that provides a structured and efficient methodology to streamline a process [25]. Significance of the application of Taguchi methods and its variants in different industrial applications is evident from the works of Mota-Gutiérrez et al. [26], Jeyapaul et al. [27], Beyer and Sendhoff [28], and Bendell et al. [29]. Among others, Taguchi's approach was considered by the researchers to address process improvement in food [30-32], healthcare [33], electronics [34], and manufacturing [35,36] industries.

\subsection{Factor Selection and Their Levels}

In this study, three controllable parameters, i.e., weight of untreated beads (A), batch duration (B), and temperature $(C)$, each at three levels are considered. The factors and their levels are selected after observing, and by consulting with the experienced operators that are involved in the pod production process at the facility. In general, factor levels are equally spaced as closely as possible to the lower and upper bounds. Even though the factor levels are continuous, they are not theoretically equidistant in the case of 'weight of untreated beads' and 'batch duration' factors due to operational constraints to conform to the market requirements. Table 2 shows the selected factors and their levels.

Table 2. Factors and their levels.

\begin{tabular}{cccccc}
\hline \multirow{2}{*}{ Factors } & \multirow{2}{*}{ Unit } & Symbol & \multicolumn{3}{c}{ Levels } \\
\cline { 4 - 6 } & & & $\mathbf{1}$ & $\mathbf{2}$ & $\mathbf{3}$ \\
\hline Weight of untreated beads & $\mathrm{kg}$ & $\mathrm{A}$ & 17 & 20 & 22 \\
Batch duration & $\mathrm{S}$ & $\mathrm{B}$ & 130 & 140 & 145 \\
Temperature & ${ }^{\circ} \mathrm{F}$ & $\mathrm{C}$ & 145 & 150 & 155 \\
\hline
\end{tabular}

\subsection{Experimental Design}

Taguchi method involves an experimental layout as an orthogonal array that has various combinations of the levels of the factors that correspond to each experiment Phadke [37]. In this study, an $\mathrm{L}_{27}$ orthogonal array as shown in Table 3 is used. Through this orthogonal array, not only the effect of main factors, but also the interaction effects, if any, of the factors can be easily investigated [25]. This orthogonal array suits the experimental design for the factors and their levels considered in the study. The $\mathrm{L}_{27}$ orthogonal array has twenty-six degrees of freedom and it can be used to perform the experiments required in this study. The degree of freedom of an orthogonal array is obtained by subtracting 1 from total number of experiments of the array. $L_{27}$ orthogonal array has 27 experiments and, therefore, its degree of freedom is $26(27-1=26)$. Based on the data that were obtained for the study, the experimental layout for three factors each at three levels is shown in Table 3. In this layout, each row represents a trial condition or experiment that involves the factors that were included in the study at different levels. For each trial run, three replicates of the response variable i.e., the weight of 
the expanded beads are observed. These trial runs are carried out on the random basis to avoid the influence of the experimental setup during data collection [25].

Table 3. Taguchi experiments based on $\mathrm{L}_{27}$ orthogonal array design.

\begin{tabular}{ccccccc}
\hline $\begin{array}{c}\text { Experiment } \\
\text { Number }\end{array}$ & $\begin{array}{c}\text { Weight of Untreated } \\
\text { Beads (Kg) }\end{array}$ & $\begin{array}{c}\text { Batch } \\
\text { Duration }\end{array}$ & $\begin{array}{c}\text { Temperature } \\
\left({ }^{\circ} \mathbf{F}\right)\end{array}$ & \multicolumn{2}{c}{ Weight of the Expanded Beads (in Grams) } \\
\cline { 5 - 6 } & 17 & 130 & 145 & 16.12 & 16.70 & 16.84 \\
\hline 1 & 17 & 140 & 150 & 16.00 & 17.40 & 17.60 \\
2 & 17 & 145 & 155 & 15.10 & 15.40 & 15.39 \\
3 & 20 & 130 & 145 & 15.30 & 16.00 & 16.30 \\
4 & 20 & 140 & 150 & 15.45 & 15.45 & 15.60 \\
5 & 20 & 145 & 155 & 15.10 & 14.25 & 14.00 \\
6 & 22 & 130 & 145 & 17.00 & 18.60 & 18.14 \\
7 & 22 & 140 & 150 & 17.15 & 17.00 & 17.60 \\
8 & 22 & 145 & 155 & 16.24 & 15.00 & 15.36 \\
9 & 17 & 130 & 150 & 14.21 & 14.66 & 14.80 \\
10 & 17 & 140 & 155 & 14.09 & 14.32 & 15.00 \\
11 & 17 & 145 & 145 & 14.42 & 15.11 & 15.00 \\
12 & 20 & 130 & 150 & 14.22 & 14.30 & 14.90 \\
13 & 20 & 140 & 155 & 15.00 & 14.11 & 14.23 \\
14 & 20 & 145 & 145 & 16.24 & 15.00 & 16.12 \\
15 & 130 & 150 & 15.30 & 16.50 & 15.81 \\
16 & 22 & 140 & 155 & 15.10 & 15.90 & 16.00 \\
17 & 22 & 145 & 145 & 17.21 & 17.40 & 17.90 \\
18 & 22 & 130 & 155 & 13.54 & 13.00 & 14.42 \\
19 & 17 & 140 & 145 & 14.22 & 15.65 & 14.55 \\
20 & 17 & 145 & 150 & 14.11 & 14.76 & 14.92 \\
22 & 17 & 130 & 155 & 15.00 & 14.50 & 14.25 \\
23 & 20 & 140 & 145 & 16.00 & 17.50 & 17.60 \\
24 & 20 & 145 & 150 & 15.30 & 15.70 & 15.00 \\
27 & 20 & 130 & 155 & 16.00 & 16.32 & 16.76 \\
\hline
\end{tabular}

\section{Results}

As per the experimental design that is shown in Table 3, twenty-seven experiments were performed and the results were analysed while using Minitab software. Minitab is a user friendly statistical analysis and graphical package which is widely used by the academicians, researchers and professionals as an analysis tool for descriptive statistics, inferential statistics, design, and analysis of experiments including Taguchi design of experiments and for many other statistical applications. For example, Zhang and de Dear [38] used Minitab 17 to analyse the data collected through Taguchi's design of experiment to optimise thermal comfort and cognitive performance during direct load control events. For the analyses of the results, the $\mathrm{S} / \mathrm{N}$ ratio, the analysis of mean (ANOM), and the analysis of variance (ANOVA) were employed and discussed in the following sections. Optimal setting of the parameters of the pod production process was determined based on the results of these analyses, which was also verified through confirmation experiment.

\subsection{Analysis of Signal-to-Noise (S/N) Ratio}

In the Taguchi method, signal represents the target value (mean) and noise represents the undesirable value (standard deviation) for the response variable. In other words, the $\mathrm{S} / \mathrm{N}$ ratio is the ratio of the target value to the deviation from its mean. The Taguchi method emphasises the significance of the signal-to-noise $(\mathrm{S} / \mathrm{N})$ ratio with regard to variation in the response variable (weight of the expanded beads). For calculating the $\mathrm{S} / \mathrm{N}$ ratio, the smaller-the-better quality characteristic is chosen and it is calculated using Equation (2). The unit of measurement of $\mathrm{S} / \mathrm{N}$ ration is decibel (dB). 
This quality characteristic is also used in the work of other researchers, such as Günayand Yücel [39] and Nalbant et al. [40], to minimise the surface roughness in their respective studies.

$$
S / N=-10 \log _{10} \frac{1}{n} \sum_{i=1}^{n} y_{i}^{2}
$$

In Equation (2), $n$ is the number of experiments and $y_{i}$ is the value of the response variable for the $i$ th experiment. Table 4 shows the average values of the response variable and their corresponding $\mathrm{S} / \mathrm{N}$ ratios for all 27 experiments that were carried out randomly.

Table 4. Experimental data and Signal-to-Noise (S/N) ratio.

\begin{tabular}{|c|c|c|c|c|c|}
\hline \multirow{2}{*}{ Exp. No. } & \multicolumn{3}{|c|}{ Factors } & \multirow{2}{*}{ Average Response } & \multirow{2}{*}{ S/N Ratio (dB) } \\
\hline & A & B & $\mathrm{C}$ & & \\
\hline 1 & 1 & 1 & 1 & 16.55 & -24.38 \\
\hline 2 & 1 & 2 & 2 & 17.00 & -24.61 \\
\hline 3 & 1 & 3 & 3 & 15.30 & -23.69 \\
\hline 4 & 2 & 1 & 1 & 15.87 & -24.01 \\
\hline 5 & 2 & 2 & 2 & 15.50 & -23.81 \\
\hline 6 & 2 & 3 & 3 & 14.45 & -23.20 \\
\hline 7 & 3 & 1 & 1 & 17.91 & -25.06 \\
\hline 8 & 3 & 2 & 2 & 17.25 & -24.74 \\
\hline 9 & 3 & 3 & 3 & 15.53 & -23.83 \\
\hline 10 & 1 & 1 & 2 & 14.56 & -23.26 \\
\hline 11 & 1 & 2 & 3 & 14.47 & -23.21 \\
\hline 12 & 1 & 3 & 1 & 14.84 & -23.43 \\
\hline 13 & 2 & 1 & 2 & 14.47 & -23.21 \\
\hline 14 & 2 & 2 & 3 & 14.45 & -23.20 \\
\hline 15 & 2 & 3 & 1 & 15.79 & -23.97 \\
\hline 16 & 3 & 1 & 2 & 15.87 & -24.01 \\
\hline 17 & 3 & 2 & 3 & 15.67 & -23.90 \\
\hline 18 & 3 & 3 & 1 & 17.50 & -24.86 \\
\hline 19 & 1 & 1 & 3 & 13.65 & -22.70 \\
\hline 20 & 1 & 2 & 1 & 14.81 & -23.41 \\
\hline 21 & 1 & 3 & 2 & 14.60 & -23.29 \\
\hline 22 & 2 & 1 & 3 & 14.58 & -23.28 \\
\hline 23 & 2 & 2 & 1 & 17.03 & -24.63 \\
\hline 24 & 2 & 3 & 2 & 15.33 & -23.71 \\
\hline 25 & 3 & 1 & 3 & 16.36 & -24.28 \\
\hline 26 & 3 & 2 & 1 & 18.32 & -25.26 \\
\hline 27 & 3 & 3 & 2 & 16.68 & -24.44 \\
\hline
\end{tabular}

\subsection{Analysis of Mean (ANOM)}

Analysis of mean (ANOM) was performed to obtain the mean value of $\mathrm{S} / \mathrm{N}$ ratio at each level of the three factors. Table 5 presents the results of ANOM. In Table 5, Delta is used to rank the factors, so as to compare the relative magnitude of factor's effect on the response variable. The value of Delta is calculated as the difference between the highest average and the lowest average for each factor considered in the study. The ranks are assigned based on the Delta values. The higher the Delta value, the higher is the rank. For instance, Delta values of $0.94,0.85$, and 0.28 are given the ranks of 1,2 , and 3 to factors: weight of untreated beads (A), batch duration (B), and temperature (C), respectively. 
Table 5. Results of Analysis of Means (ANOM) for S/N ratio.

\begin{tabular}{cccc}
\hline \multirow{2}{*}{ Level } & \multicolumn{3}{c}{ Factors } \\
\cline { 2 - 4 } & A & B & C \\
\hline 1 & -23.55 & -23.80 & -24.33 \\
2 & -23.67 & -24.08 & -23.90 \\
3 & -24.49 & -23.82 & -23.48 \\
Delta & 0.94 & 0.28 & 0.85 \\
Rank & 1 & 3 & 2 \\
\hline
\end{tabular}

Table 5 reveals that the response variable is highly sensitive to the weight of untreated beads (A), followed by temperature (C) and the batch duration (B). Figure 10 shows main effects plot for the $\mathrm{S} / \mathrm{N}$ ratios of the response considered in the study. Figures 1 and 10, Figures 2 and 3 represent three levels of the factors (A, B, and C), the blue dot points for each factor represent the average $\mathrm{S} / \mathrm{N}$ ratio at these levels of the factors and the blue line is the connecting line of three points.

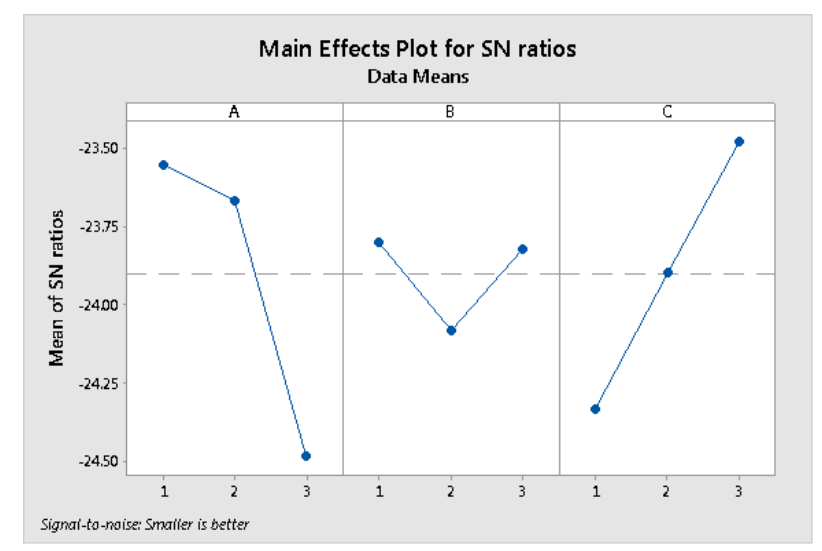

Figure 10. Main effects plot for $\mathrm{S} / \mathrm{N}$ ratios.

The slope of the line that is shown in Figure 10 indicates that the presence of effects and the degree of the slope is proportional to the magnitude of the main effect. For robust optimal solution, the optimal setting is obtained while using the $\mathrm{S} / \mathrm{N}$ ratio, in which the highest value of the factor levels is identified, regardless of the quality characteristic. A high $\mathrm{S} / \mathrm{N}$ ratio indicates that there is high sensitivity with the least error of measurement. Based on the results that are presented in Table 5 and Figure 10, the optimal combination of the input parameters and their levels is $A_{1} B_{1} C_{3}$. Therefore, the production process should be operated with $17 \mathrm{Kg}$ of untreated bead, batch duration of $130 \mathrm{~s}$, and at a temperature of $155^{\circ} \mathrm{F}$ to minimise the response variable.

The plot that is presented in Figure 11 shows the normal plot for $\mathrm{S} / \mathrm{N}$ ratios which is used to verify whether the residuals are normally distributed or not. Analysis of variance (ANOVA) is a valid analysis technique only when the residuals are normally distributed and it needs to be verified while using a normal probability plot shown in Figure 11. It is evident from Figure 11 that the residual points (blue dot points) either fall on the straight line (drawn at $45^{\circ}$ with the $x$-axis) or are extremely close to the line. No unusual pattern is observed from Figure 11, which indicates that the residuals are normally distributed. Thus, the normality assumption of the experimental data, which is essential for performing ANOVA, is verified. ANOVA is discussed in the following section. 


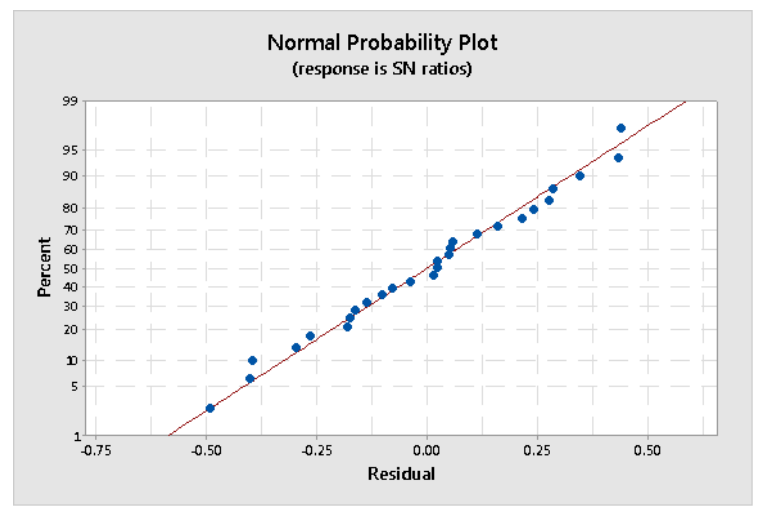

Figure 11. Normal probability plot for $\mathrm{S} / \mathrm{N}$ ratios.

\subsection{Analysis of Variance (ANOVA)}

Analysis of Variance is a statistical tool that is used to determine the significance of the input factors and their interactions with regard to the response variable. ANOVA is performed to determine the relative importance amongst the factors and to identify differences in the average performance of the data that were considered in the study. This is required, so that optimal combinations of the factor levels can be identified with more accuracy. In other words, the purpose of ANOVA is to identify which factors significantly affect the response variable that is considered in the study. A similar work using the Taguchi method and ANOVA was performed by Altan [41] and Altan and Yurd [42] to identify the optimal conditions in order to minimise the shrinkage of polypropylene and polystyrene. Kamaruddin et al. [43] also used the Taguchi's approach to optimise polypropylene and polyethylene blends through the injection moulding process. ANOVA was also performed by Shen et al. [44] and Goel et al. [45] to optimise the injection moulding and slab milling process parameters, respectively. To perform ANOVA, the total sum of squared deviations $\left(S S_{T}\right)$ from the mean $\mathrm{S} / \mathrm{N}$ ratio $\mathrm{\eta}_{m}$ is calculated while using Equation (3).

$$
S S_{T}=\sum_{i=1}^{n}\left(\mathrm{y}_{i}-\mathrm{y}_{m}\right)^{2}
$$

where, $n$ is the number of experiments in the orthogonal array, $\mathrm{y}_{i}$ is the mean $\mathrm{S} / \mathrm{N}$ ratio for the $i$ th experiment, and $\mathrm{\eta}_{m}$ is the grand mean i.e., mean of $\mathrm{S} / \mathrm{N}$ ratio of all 27 experiments. Further calculations were carried out to perform ANOVA, the results of which are presented in Table 6.

Table 6. Results of Analysis of Variance (ANOVA).

\begin{tabular}{ccccccc}
\hline Symbol & $\begin{array}{c}\text { Degrees of } \\
\text { Freedom }\end{array}$ & Sum of Squares & $\begin{array}{c}\text { Adjusted Sum of } \\
\text { Square }\end{array}$ & $\begin{array}{c}\text { Adjusted Mean } \\
\text { Square }\end{array}$ & $\boldsymbol{F}$ \\
\hline A & 2 & 4.6601 & 4.66009 & 2.33004 & 11.30 \\
B & 2 & 0.4486 & 0.44862 & 0.22431 & 1.09 & 0.005 \\
C & 2 & 3.3149 & 3.31490 & 1.65745 & 8.04 & 0.012 \\
AB & 4 & 0.0396 & 0.03957 & 0.00989 & 0.05 \\
AC & 4 & 0.4348 & 0.43484 & 0.10871 & 0.53 \\
BC & 4 & 1.0909 & 1.09091 & 0.27273 & 1.32 \\
Residual Error & 8 & 1.6490 & 1.64900 & 0.20613 & 0.340 \\
\hline Total & 26 & 11.6379 & & & \\
\hline
\end{tabular}

The results of ANOVA that are presented in Table 6 reveal that weight of untreated beads (A) and temperature (C) significantly affect the response variable, as depicted by their low $p$-values $(p<0.05)$ and high $F$ values. Among three factors, the least contributing factor is the batch duration (B) with relatively high $p$-value and considerably low $F$ value. Further, Table 6 also shows that the two way interaction between factors i.e., $\mathrm{AB}, \mathrm{AC}$, and $\mathrm{BC}$ are also statistically not significant, as their $p$ values are much more than 0.05 . 


\subsection{Factor Interactions}

In the interaction plot, the means for each factor level are mapped to the constant level of the other factor. Interaction plots are helpful in identifying the presence and degree of interaction between the factors that were considered in the study. Interaction at a factor level is identified subject to the response observed from the levels of the other factors. Whereas, no overlaps in the interaction plot indicate no interaction among the factors. In this study, three interaction plots for $\mathrm{AB}, \mathrm{AC}$, and $\mathrm{BC}$ were obtained and were not found to be significant and, therefore, the interaction plots were not included in this paper. The insignificance of the interaction between factors is also evident from ANOVA results (Table 6).

\subsection{Confirmation Experiment}

Taguchi recommended to conduct the confirmation experiment as a final step to measure the impact of the optimal setting of the process [46]. This step is carried out to verify the improvement of the response variable while using the optimum level of each parameter based on the results of the analyses that were discussed in the earlier sections. After establishing the significant factors and identifying their optimal level $\left(A_{1} B_{1} C_{3}\right)$, the estimated value of $S / N$ ratio i.e., $\mathfrak{y}$, using the optimal level of the parameters, can be calculated through Equation (4). In Equation (4), $\mathrm{y}_{m}$ is the grand mean of $S / \mathrm{N}$ ratio, $\grave{\mathrm{y}}_{i}$ is the mean $\mathrm{S} / \mathrm{N}$ ratio at the optimal level for the factor, and $o$ is the number of the main factors that affect the quality characteristic.

$$
\grave{\mathrm{n}}=\mathrm{\eta}_{m}+\sum_{i=1}^{o}\left(\grave{\mathfrak{\eta}}_{i}-\mathrm{\eta}_{m}\right)
$$

The results of the confirmation experiment, as presented in Table 7, indicate that, at an optimal setting, a difference of $1.41 \%$ between the experimental value and predicted values of $\mathrm{S} / \mathrm{N}$ ratio is obtained, which shows a close agreement between the experimental and predicted values. Scanning Electron Microscope (SEM) images of the beads that were obtained at the initial condition i.e., $\mathrm{A}_{2} \mathrm{~B}_{2} \mathrm{C}_{3}$ (Figure 12) and optimal parameter setting i.e., $A_{1} B_{1} C_{3}$ (Figure 13) were captured to study the changes in the treated beads. In addition, a similar image was also obtained for the beads collected after the confirmation experiment (Figure 14). For all of the SEM images, the samples were coated with chromium in a Quorum EMS 150T ES sputter coater. They were coated at a $45^{\circ}$ angle from opposite directions at $80 \mathrm{~mm}$ from the target for $180 \mathrm{~s}$ and each coat was made at $120 \mathrm{~mA}$. The samples were examined in a JEOL IT-300 scanning electron microscope. The microscope was used in high vacuum with a magnification of 100x. The acceleration voltage was $5 \mathrm{kV}$, Probe current (beam intensity) 30, aperture 3 , and working distance of approximately $40 \mathrm{~mm}$.

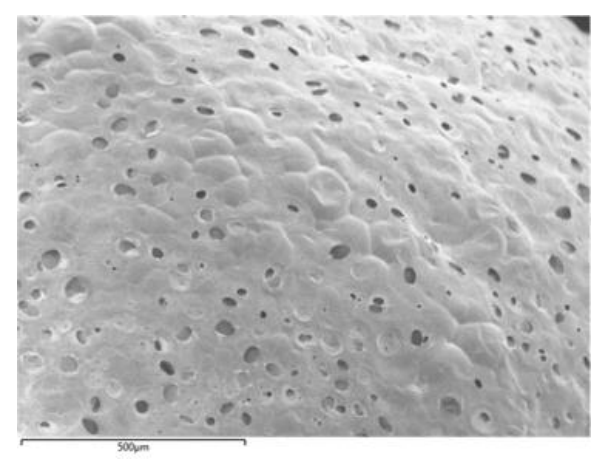

Figure 12. Experiment 14, SEM image of the treated bead at the initial parameter setting of $\mathrm{A}_{2} \mathrm{~B}_{2} \mathrm{C}_{3}$ at magnification $100 \times$ and acceleration voltage of $5 \mathrm{kV}$. 


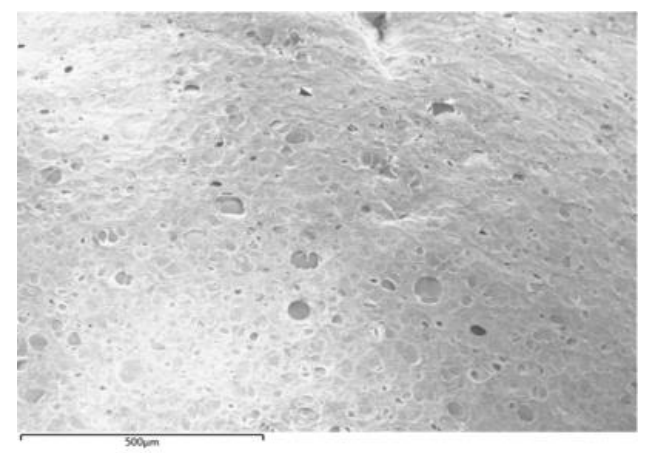

Figure 13. Experiment 19, SEM image of the treated bead at the optimal parameter setting of $A_{1} B_{1} C_{3}$ atmagnification $100 \times$ and acceleration voltage of $5 \mathrm{kV}$.

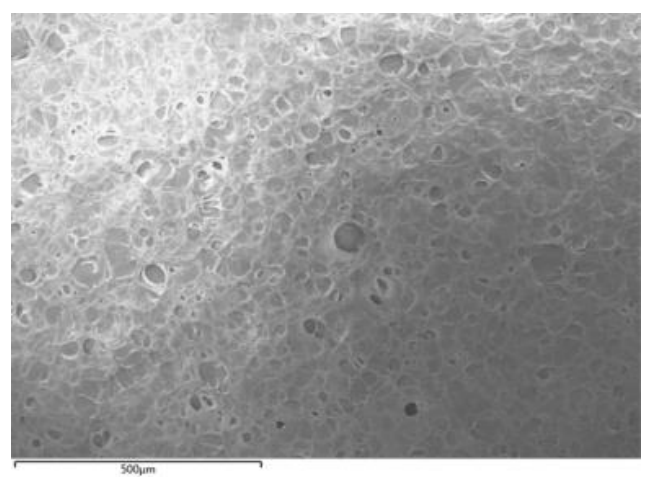

Figure 14. SEM image of the treated bead at the confirmation experiment at the optimal parameter setting of $A_{1} B_{1} C_{3}$ at magnification $100 \times$ and acceleration voltage of $5 \mathrm{kV}$.

In comparison to Figures 12-14, exhibit a significant difference in the morphological structure of the over exposed bead, as shown in Figure 6. Based on the morphological structures of the treated beads, it is observed that the beads that were obtained from the optimal setting (Figure 13) are different than the ones that were obtained while using the initial parameter setting (Figure 12). However, the structure of the beads obtained from the confirmation experiment (Figure 14) is almost similar to the bead obtained at the optimal setting. Furthermore, based on the optimal experimental value, the weight of the beads observed is $13.82 \mathrm{~g}$. It is evident from Table 7 that the experimental results are reasonably correlated with the predicted result. The results in Table 7 also indicate that there is an improvement of $0.5 \mathrm{~dB}$ in the $\mathrm{S} / \mathrm{N}$ ratio as compared to the initial level of parameters.

Table 7. Results of the confirmation experiment.

\begin{tabular}{|c|c|c|c|c|c|}
\hline & \multirow{2}{*}{$\begin{array}{c}\text { Initial } \\
\text { Parameters }\end{array}$} & \multicolumn{2}{|c|}{ Optimal Parameters } & \multirow{2}{*}{$\begin{array}{l}\text { Difference } \\
\text { (E-P) }\end{array}$} & \multirow{2}{*}{ \% Difference } \\
\hline & & Experimental (E) & Prediction (P) & & \\
\hline Level & $\mathrm{A}_{2} \mathrm{~B}_{2} \mathrm{C}_{3}$ & $\mathrm{~A}_{1} \mathrm{~B}_{1} \mathrm{C}_{3}$ & $\mathrm{~A}_{1} \mathrm{~B}_{1} \mathrm{C}_{3}$ & - & - \\
\hline $\mathrm{S} / \mathrm{N}$ ratio $(\mathrm{dB})$ & -23.20 & -22.70 & -23.02 & 0.32 & 1.41 \\
\hline
\end{tabular}

\section{Conclusions}

Pods are essential components that were used in the construction industry to provide under floorings and insulation in the buildings. The quality of pod plays a significantly important role in providing desired characteristics to the buildings. Pod quality, in turn, depends upon the optimal setting of the process parameters, which is used for its manufacturing and, therefore, optimal setting of the parameters needs to be determined. This study demonstrated the application of the widely used Taguchi method in the determination of the optimal combination of the process parameters that yields the minimum weight of the expanded beads. In this study, the effect of three important parameters of 
pod production process i.e., weight of untreated beads, batch duration, and temperature on the weight of the expanded beads is explored. Based on the results that were obtained from the analysis of the experimental data using Taguchi's $L_{27}$ orthogonal array, it is found that, within the range investigated, the optimal setting of the parameters is $A_{1} B_{1} C_{3}$. The two way interactions between the factors are not found to be significant. For consistent performance and good quality production of the beads, the production process is suggested to be operated with the weight of untreated beads at $17 \mathrm{~kg}$, batch duration of $130 \mathrm{~s}$, and the temperature at $155^{\circ} \mathrm{F}$. This optimal combination of the process parameters yields a consistent weight of the expanded beads. Furthermore, the confirmatory experiment showed that, at optimal parameter settings, a reasonably streamlined and robust pod manufacturing process can be achieved. Moreover, the confirmation experiments also indicated that, at optimal combination of the parameters, there is no significant difference between the experimental and predicted values of the $\mathrm{S} / \mathrm{N}$ ratio. It is emphasized that improved and streamlined processes, such as pod production in the EPS supply chain, can be helpful for the manufacturers to streamline their production operations and mitigate waste in the chain. Thus, in continuation to this work, a longitudinal study may be carried out in the future to assess the impact of EPS waste during the pod production process by capturing the Cost of Quality (COQ) in the downstream chain activities.

Author Contributions: S.I.I. and R.G.: concept design and experimentation, Z.A.K. and A.N.S.: literature review, S.J.: analysis of result, S.I.I., Z.A.K. and S.J.: discussion, I.A.B. and A.A.: preparation of the manuscript, review/revision, fund acquisitions.

Funding: This work is funded by Deanship of Scientific Research at King Khalid University under grant number (R.G.P. 2/11/39).

Acknowledgments: The authors extend their appreciation to the Deanship of Scientific Research at King Khalid University for funding this work through research groups program under grant number (R.G.P. 2/11/39). The authors also thank Ara Institute of Canterbury, New Zealand for registering the project (reg. \#1689). Furthermore, the authors express their appreciation to the management of the production facility for the support they provided during the study.

Conflicts of Interest: The authors declare no conflict of interest.

\section{Nomenclature}

$\begin{array}{ll}\text { EPS } & \text { Expanded polystyrene } \\ \text { TQM } & \text { Total quality management } \\ \text { OA } & \text { Orthogonal array } \\ \text { ANOM } & \text { Analysis of the means } \\ \text { ANOVA } & \text { Analysis of variance } \\ \text { SEM } & \text { Scanning electron microscope } \\ \text { PLC } & \text { Programmable logic controller } \\ \mu & \text { mean value of } Y \text { within the experiment range } \\ \alpha_{\mathrm{i}} & \text { main effects of factor A } \\ \beta_{\mathrm{j}} & \text { main effects of factor B } \\ \mathrm{e}_{\mathrm{ij}} & \text { Error term } \\ \mathrm{S} / \mathrm{N} & \text { Signal-to-noise ratio } \\ \mathrm{n} & \text { Number of experiments } \\ \mathrm{y}_{\mathrm{i}} & \text { Value of the response variable for the } i \text { th experiment } \\ \mathrm{SS} & \text { Total sum of squared deviations } \\ \eta_{\mathrm{i}} & \text { Mean } \mathrm{S} / \mathrm{N} \text { ratio for the } i \text { th experiment } \\ \eta_{\mathrm{m}} & \text { Grand mean i.e., mean of } \mathrm{S} / \mathrm{N} \text { ratio of all } 27 \\ \mathrm{n}_{\mathrm{n}} & \text { experiments } \\ \mathrm{y}_{i} & \text { Estimated value of } \mathrm{S} / \mathrm{N} \text { ratio } \\ \mathrm{o} & \text { Mean } \mathrm{S} / \mathrm{N} \text { ratio at the optimal level } \\ \mathrm{dB} & \text { Number of the main factors that affect the quality } \\ & \text { characteristic } \\ & \text { Decibel }\end{array}$




\section{References}

1. Fu, S.L.; Chou, S.Y.; Chen, C.K.; Wang, C.W. Assessment and cultivation of total quality management organizational culture-An empirical investigation. Total Qual. Manag. Bus. Excell. 2015, 26, 123-139. [CrossRef]

2. Gehani, R.R. Quality value-chain: A meta-synthesis of frontiers of quality movement. Acad. Manag. Exec. 1993, 7, 29-42. [CrossRef]

3. Ritchie, L.; Dale, B. Self-assessment using the business excellence model: A study of practice and process. Int. J. Prod. Econ. 2000, 66, 241-254. [CrossRef]

4. Dahlgaard-Park, S.M.; Reyes, L.; Chen, C.-K. The evolution and convergence of total quality management and management theories. Total Qual. Manag. Bus. Excell. 2018, 29, 1108-1128. [CrossRef]

5. Hietschold, N.; Reinhardt, R.; Gurtner, S. Measuring critical success factors of TQM implementation successfully-A systematic literature review. Int. J. Prod. Res. 2014, 52, 6254-6272. [CrossRef]

6. Moosa, K.; Sajid, A. Critical analysis of Six Sigma implementation. Total Qual. Manag. 2010, 21, 745-759. [CrossRef]

7. Zhou, B. Lean principles, practices, and impacts: A study on small and medium-sized enterprises (SMEs). Ann. Oper. Res. 2012, 241, 457-474. [CrossRef]

8. Horvath, J.S. Expanded Polystyrene (EPS) Geofoam: An Introduction to Material Behavior. Geotext. Geomembr. 1994, 13, 263-280. [CrossRef]

9. Chen, B.; Liu, J. Mechanical Properties of Polymer-Modified Concretes Containing Expanded Polystyrene Beads. Constr. Build. Mater. 2007, 21,7-11. [CrossRef]

10. Magalhães, F.; Lago, R.M. Floating Photocatalysts Based on TiO2 Grafted on Expanded Polystyrene Beads for the Solar Degradation of Dyes. Sol. Energy 2009, 83, 1521-1526. [CrossRef]

11. Kannan, P.; Biernacki, J.J.; Visco, D.P., Jr. A Review of Physical and Kinetic Models of Thermal Degradation of Expanded Polystyrene Foam and their Application to the Lost Foam Casting Process. J. Anal. Appl. Pyrolysis 2007, 78, 162-171. [CrossRef]

12. Varnagiris, S.; Doneliene, J.; Tuckute, S.; Cesniene, J.; Lelis, M.; Milcius, D. Expanded Polystyrene Foam Formed from Polystyrene Beads Coated with a Nanocrystalline $\mathrm{SiO} 2 \mathrm{Film}$ and the Analysis of Its Moisture Adsorption and Resistance to Mechanical Stress. Polym.-Plast. Technol. Eng. 2018, 57, 1296-1302. [CrossRef]

13. Shirazi, A.N.; Haydarian, H.; Nasehi, S.A. Shear and Compression Behaviors of Sandy and Clayey Soils Mixed with Different Sizes of Expanded Polystyrene Beads. Geotech. Geol. Eng. Int. J. 2018, 36, 3823-3830. [CrossRef]

14. Shin, C.; Chase, G.G.; Reneker, D.H. Recycled Expanded Polystyrene Nanofibers Applied in Filter Media. Colloids Surf. A Physicochem. Eng. Asp. 2005, 262, 211-215. [CrossRef]

15. Rajeev, A.; Erapalapati, V.; Madhavan, N.; Basavaraj, M.G. Conversion of expanded polystyrene waste to nanoparticles via nanoprecipitation. J. Appl. Polym. Sci. 2016, 133. [CrossRef]

16. Chen, B.; Liu, J. Properties of Lightweight Expanded Polystyrene Concrete Reinforced with Steel Fibre. Cem. Concr. Res. 2004, 34, 1259-1263. [CrossRef]

17. Sarmiento, A.M.; Guzman, H.L.; Morales, G.; Romero, D.E.; Pataquiva-Mateus, A.Y. Expanded Polystyrene (EPS) and Waste Cooking Oil (WCO): From Urban Wastes to Potential Material of Construction. Waste Biomass Valorization 2016, 7, 1245-1254. [CrossRef]

18. Chindaprasirt, P.; Waisurasingha, C.; Hiziroglu, S.; Kasemsiri, P. Properties of wood flour/expanded polystyrene waste composites modified with diammonium phosphate flame retardant. Polym. Compos. 2015, 36, 604-612. [CrossRef]

19. Park, H.S.; Kim, Y.; Oh, B.K.; Cho, T. Compressive properties of graphite-embedded expanded polystyrene for vibroacoustic engineering applications. Compos. Part B 2016, 93, 252-264. [CrossRef]

20. Gil-Jasso, N.D.; Segura-González, M.A.; Soriano-Giles, G.; Neri-Hipolito, J.; López, N.; Mas-Hernández, E.; Barrera-Diaz, C.E.; Varela-Guerrero, V.; Ballesteros-Rivas, M.F. Dissolution and recovery of waste expanded polystyrene using alternative essential oils. Fuel 2019, 239, 611-616. [CrossRef]

21. Jimenez-Francisco, M.; Caamal-Canche, J.A.; Carrillo, J.G.; Cruz-Estrada, R.H. Performance Assessment of a Composite Material Based on Kraft Paper and a Resin Formulated with Expanded Polystyrene Waste: A Case Study from Mexico. J. Polym. Environ. 2018, 26, 1573-1580. [CrossRef]

22. Singhal, R.; Ishita, I.; Sow, P.K. Integrated Polymer Dissolution and Solution Blow Spinning Coupled with Solvent Recovery for Expanded Polystyrene Recycling. J. Polym. Environ. 2019, 27, 1240-1251. [CrossRef] 
23. Hinkelmann, K. Design of Experiments Volume Three: Special Designs and Applications; Wiley-Interscience: Hoboken, NJ, USA, 2012.

24. Davim, J.P. Design of Experiments in Production Engineering, 1st ed.; Springer International: Cham, Switzerland, 2016.

25. Roy, R.K. Design of Experiments Using the Taguchi Approach: 16 Steps to Product and Process Improvement; Wiley-Interscience: New York, NY, USA, 2001.

26. Mota-Gutiérrez, C.G.; Reséndiz-Flores, E.O.; Reyes-Carlos, Y.I. Mahalanobis-Taguchi system: State of the art. Int. J. Qual. Reliab. Manag. 2018, 35, 596-613. [CrossRef]

27. Jeyapaul, R.; Shahabudeen, P.; Krishnaiah, K. Quality Management Research by Considering Multi-response Problems in the Taguchi Method-A Review. Int. J. Adv. Manuf. Technol. 2005, 26, 1331-1337. [CrossRef]

28. Beyer, H.-S.; Sendhoff, B. Robust Optimization-A Comprehensive Survey. Comput. Methods Appl. Mech. Eng. 2007, 196, 3190-3218. [CrossRef]

29. Bendell, A.; Disney, J.; Pridmore, W.A. Taguchi Methods: Applications in World Industry; IFS Publications: London, UK, 1989.

30. Patel, S.R.; Murthy, Z.Y.P. Optimization of process parameters by Taguchi method in the recovery of lactose from whey using sonocrystallization. Cryst. Res. Technol. 2010, 45, 747-752. [CrossRef]

31. Besseris, G.J. Multi-response unreplicated-saturated Taguchi designs and super-ranking in food formulation improvement. Int. J. Qual. Reliab. Manag. 2009, 26, 341-368. [CrossRef]

32. Charteris, W. Taguchi's system of experimental design and data analysis: A quality engineering technology for the food industry. Int. J. Dairy Technol. 1992, 45, 33-49. [CrossRef]

33. Arslanoglu, N.; Yigit, A. Experimental investigation of radiation effect on human thermal comfort by Taguchi method. Appl. Therm. Eng. 2016, 92, 18-23. [CrossRef]

34. Amalu, E.H.; Ekere, N.; Zarmai, M.; Takyi, G. Optimisation of thermo-fatigue reliability of solder joints in surface mount resistor assembly using Taguchi method. Finite Elem. Anal. Des. 2015, 107, 13-27. [CrossRef]

35. Pan, J.-N. A new loss function-based method for evaluating manufacturing and environmental risks. Int. J. Qual. Reliab. Manag. 2007, 24, 861-887. [CrossRef]

36. Perona, M. Manufacturing conformity assessment through Taguchi's quality loss function. Int. J. Qual. Reliab. Manag. 1998, 15, 931-946. [CrossRef]

37. Phadke, M.S. Quality Engineering using Robust Design, 1st ed.; Prentice-Hall: Englewood Cliffs, NJ, USA, 1989.

38. Zhang, F.; de Dear, R. Application of Taguchi method in optimising thermal comfort and cognitive performance during direct load control events. Build. Environ. 2017, 111, 160-168. [CrossRef]

39. Günay, M.; Yücel, E. Application of Taguchi Method for Determining Optimum Surface Roughness in Turning of High-Alloy White Cast Iron. Measurement 2013, 46, 913-919. [CrossRef]

40. Nalbant, M.; Gökkaya, H.; Sur, G. Application of Taguchi Method in the Optimization of Cutting Parameters for Surface Roughness in Turning. Mater. Des. 2007, 28, 1379-1385. [CrossRef]

41. Altan, M. Reducing shrinkage in injection moldings via the Taguchi, ANOVA and neural network methods. Mater. Des. 2010, 31, 599-604. [CrossRef]

42. Altan, M.; Yurd, M.E. Optimization of Residual Stresses in the Surface Regions of Injection Moldings. Polym.-Plast. Technol. Eng. 2009, 49, 32-37. [CrossRef]

43. Kamaruddin, S.; Khan, Z.A.; Foong, S.H. Quality characteristic improvement of an injection moulding product made from blends plastic by optimizing the injection moulding parameters using Taguchi method. Int. J. Plast. Technol. 2010, 14, 152-166. [CrossRef]

44. Shen, C.; Wang, L.; Li, Q. Optimization of Injection Molding Process Parameters Using Combinations of Artificial Neural Network and Genetic Algorithm Method. J. Mater. Process. Technol. 2007, 183, 412-418. [CrossRef]

45. Goel, P.; Khan, Z.; Siddiquee, A.; Kamaruddin, S.; Gupta, R. Influence of slab milling process parameters on surface integrity of HSLA: A multi-performance characteristics optimization. Int. J. Adv. Manuf. Technol. 2012, 61, 859-871. [CrossRef]

46. Ross, P.J. Taguchi Techniques for Quality Engineering: Loss Function, Orthogonal Experiments, Parameter and Tolerance Design; McGraw-Hill International Edition: Singapore, 1996.

(C) 2019 by the authors. Licensee MDPI, Basel, Switzerland. This article is an open access article distributed under the terms and conditions of the Creative Commons Attribution (CC BY) license (http://creativecommons.org/licenses/by/4.0/). 